\title{
Blast Furnace Pellet Textures during Reduction and Correlation to Strength
}

\author{
Ulrika LEIMALM, ${ }^{1,5)}$ Seija FORSMO, ${ }^{2)}$ Anna DAHLSTEDT, ${ }^{3)}$ Lena Sundqvist ÖKVIST ${ }^{4)}$ and Bo BJÖRKMAN ${ }^{1)}$ \\ 1) Division of Mineral Processing and Process Metallurgy, Luleå University of Technology, SE-971 87 Luleå, Sweden. \\ E-mail: ulrika.leimalm@ltu.se; bo.bjorkman@|tu.se \\ 2) LKAB R\&D, SE-983 81 Malmberget, Sweden. E-mail: seija.forsmo@lkab.com \\ 3) LKAB R\&D, Box 952, SE-971 28 Luleå, Sweden. E-mail: anna.dahlstedt@|kab.com \\ 4) Swerea MEFOS AB, SE-971 25 Luleå, Sweden. E-mail: lena.sundqvist@swerea.se \\ 5) Current Affiliation, SSAB Oxelösund, SE-613 80 Oxelösund, Sweden. E-mail: ulrika.leimalm@ssab.com
}

(Received on May 20, 2010; accepted on July 7, 2010)

\begin{abstract}
The blast furnace is the most common means of producing hot metal. As the amounts of reduction agents increases, which influence in-furnace conditions such as ascending gas properties, temperature profiles and the ore-to-coke ratio, new demands are put on the iron-bearing material in terms of both reducibility and mechanical strength. To investigate the possibilities to use the Pellet Multi Press (PMP) equipment for compression strength measurements of reduced pellets and to gain a deeper understanding of the correlation between pellet texture and strength, an initial study of pellets taken from the LKAB Experimental Blast Furnace (EBF) was conducted. Furthermore, the pellet pieces generated after compression tests were characterized using light optical microscopy. In order to correlate the texture of pellet pieces to the pellet texture prior to breakage, a characterization of the chronological pellet texture development during reduction in the EBF was performed. The original pellet texture remained in the beginning of reduction and differences receded through the EBF shaft as wustite and $\mathrm{Fe}_{\text {met }}$ was formed. Occurrence of $\mathrm{Fe}_{\text {met }}$ in the pellet texture increased the compression strength, while less reduced and less sintered textures showed the reverse effect. So far, the results from compression strength tests indicate that disintegration of pellets takes place at a reaction front, at the transition between different texture types of iron oxide or at the location of a visible surface crack.
\end{abstract}

KEY WORDS: blast furnace; pellet texture; reduction; pellet strength.

\section{Introduction}

The blast furnace is the most common means of producing hot metal. In order to continuously reduce coke consumption, efforts are made to replace coke by increased amounts of injected reduction agents. An increase in e.g., injected pulverized coal will influence in-furnace conditions such as ascending gas properties and temperature profiles. The altered conditions for reduction and the increased ore-to-coke ratio will put new demands on the iron-bearing material in terms of both reducibility and mechanical strength. In Sweden, blast furnaces are operated with 100\% pellets as the iron-bearing material. The strength of fired iron ore pellets is determined as crushing strength according to ISO 4700 and as tumble strength according to ISO 3271 . $^{1)}$ In order to determine the disintegration of pellets under conditions corresponding to those existing at commencement of reduction in the upper part of the blast furnace shaft, the low-temperature reduction-disintegration test according to ISO 13930 is used. The Swedish pellet producer LKAB frequently uses tumbling for testing of material strength on pellets reduced by the ISO 4695 test or on reduced pellets taken out with shaft probes in the LKAB
Experimental Blast Furnace (EBF). ${ }^{2)}$ Results from the strength tests for reduced pellets are presented as material fractions in relation to size. Lu et al. ${ }^{3)}$ investigated the loss of mechanical strength of three types of Canadian iron ore pellets (i.e., acid, limestone and fluxed pellets) at various degrees of reduction under laboratory conditions programmed relevant to blast furnace operation. At lower temperatures, all pellet types lost part of their strengths, which to some extension was regained at higher temperatures for limestone and acid pellets at temperatures when iron/ wustite was observed near the surface. It was proposed that it would not be possible to measure the strength at room temperatures, since neither wustite nor the binder phase has the same properties at room temperatures as at $1000^{\circ} \mathrm{C} .^{4)} \mathrm{In}$ the actual blast furnace, the low mechanical strength of wustite in the chemical reserve zone makes this zone critical for disintegration or compression. Compression measurements at relevant temperatures using a high-temperature compression machine with adjustable atmosphere showed that pellets with an original strength higher than $2000 \mathrm{~N}$ roughly kept a high-temperature strength over $1000 \mathrm{~N}^{5)}$ The measured strength was judged to be sufficiently high to avoid damage in the blast furnace. 
To gain a better understanding of pellet strength, it is of interest to evaluate possible correlations between degradation and pellet textures obtained during reduction. LKAB has built a semi-automatic compression strength (CS) testing device called Pellet Multi Press (PMP), which was earlier used to study binding mechanisms in wet and dry iron ore green pellets. ${ }^{6}$ It enables a possibility for accurate and repeatable CS measurements and advanced data analysis of the compression pressure curves. The use of the PMP equipment in the present study offered a unique opportunity to evaluate the method for CS-tests of pellets taken out at different shaft levels in the EBF. In addition, initial results to gain increased knowledge about the relation between pellet texture and pellet breakage properties were attained. In order to correlate the texture of pellet pieces to the pellet texture prior to breakage, a characterization of the chronological pellet texture development during reduction in the EBF was carried out.

\section{Method}

\subsection{Material}

Commercial olivine pellets produced by LKAB were used in the investigations performed. Material samples for characterization of unreduced pellets and pellets for EBF basket samples were taken at the LKAB straight grate pelletizing plant at Malmberget. About 60 unreduced pellets were characterized. The chemical composition of the olivine pellet is presented in Table 1. In the EBF test for sampling of material by the shaft probe, the majority of the charged pellets were in the size range 9-12.5 $\mathrm{mm}$. The crushing strength of the olivine pellets, determined according to ISO 4700, was $210 \mathrm{daN}$.

\subsection{LKAB Experimental Blast Furnace}

The EBF at the LKAB ironmaking research centre has a working volume of $8.2 \mathrm{~m}^{3}$ and a diameter at tuyere level of $1.2 \mathrm{~m}$ and is equipped with a system for injection of reduction agents. The working height from tuyere level to stock line is $6 \mathrm{~m}$ and there are three tuyeres separated by $120^{\circ}$. The operation of the EBF is similar to a commercial blast furnace, although with a shorter response time. Therefore, it is a valuable tool for detecting differences in properties of ferrous burden materials as well as different injection agents and new process concepts. Coke and injection coal are used as reducing agents. To obtain a desired slag basicity and volume, quartzite, BOF slag and limestone are used as slag formers.

There are two horizontal shaft probes located in the upper and lower shaft, see Fig. 1, and one inclined probe at the bosh level. The upper probe is situated $4.8 \mathrm{~m}$ above tuyere level and the lower $2.33 \mathrm{~m}$ above tuyere level. The distance between the tuyeres and the stock line is $5.7 \mathrm{~m}$. The material taken out with the horizontal shaft probes is divided in sub-samples. Five sub-samples are, during ideal sampling conditions, collected from the upper shaft probe and 6 from the lower. However, it is common that 4 subsamples are received during sampling. The material taken out with the shaft probes is quickly cooled. These samples are useful in explaining process observations and differences between materials tested in EBF operation. Only a
Table 1. Chemical composition of olivine pellets in $\mathrm{wt} \%$.

\begin{tabular}{||l||llllll||}
\hline \multirow{3}{*}{ Olivine pellet } & $\mathrm{Fe}_{\text {tot }}$ & $\mathrm{FeO}$ & $\mathrm{CaO}$ & $\mathrm{SiO}_{2}$ & $\mathrm{MgO}$ & $\mathrm{Al}_{2} \mathrm{O}_{3}$ \\
\cline { 2 - 7 } & 66.7 & 0.5 & 0.45 & 1.8 & 1.3 & 0.35 \\
\hline
\end{tabular}

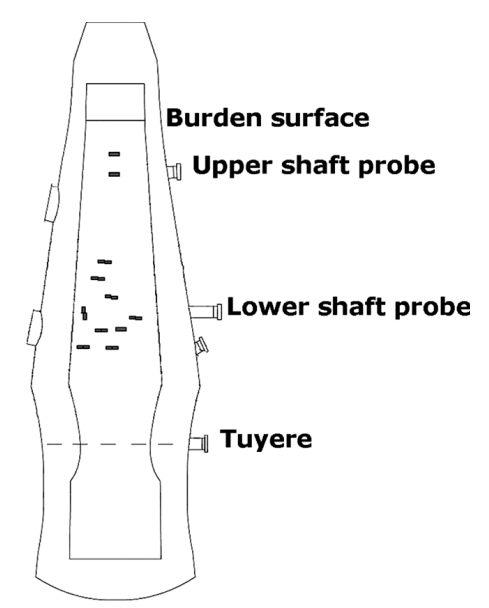

Fig. 1. Schematic drawing of the EBF. Positions of shaft probes indicated as well as recovered baskets as rectangular marks in the shaft.

limited variety of materials can be investigated, one limitation being the amount of sample needed for the actual operation.

After a campaign, the EBF can be $\mathrm{N}_{2}$ quenched and excavated. The process is interrupted, $\mathrm{N}_{2}$ throughput from the top is started, and then blast volume is decreased and finally stopped. Dissection of the EBF can start after at least ten days of cooling and carried out like an archaeological excavation, where basket samples introduced in the final hours of operation are recovered. Basket samples are charged to have samples of a wide variety exposed to EBF process conditions. It is also possible to charge a sequence of samples of a material and to analyse the reaction process in detail. The cooling of the burden and baskets at a quenching is slower than for probe samples and may have a great impact on the textures. It is also important to note that the furnace conditions in this case are set by the main burden rather than the materials in the baskets.

\subsubsection{Pellets for Characterization}

Stable and, for the EBF, normal process conditions were secured prior to in-burden sampling and quenching, respectively. The pulverized coal injection rate (PCR) was in the range $130-150 \mathrm{~kg} / \mathrm{t} \mathrm{HM}$. Pellets for characterization have been taken out with the shaft probes as well as basket samples during excavation after quenching of the EBF. The positions of basket samples recovered during excavation of the EBF are indicated in the schematic drawing of the EBF in Fig. 1. The burden settles during cooling; therefore, basket samples were situated at positions somewhat higher in the shaft when the EBF process was interrupted. From each basket sample, at least 14 pellets were characterized. At least 7 pellets taken out with the shaft probes were characterized for each radial sampling position, i.e., estimated centre and intermediate.

For determination of the pellet strength, material was taken out with the upper and lower shaft probes, respectively, on two occasions, test periods 1 and 2 . To enable 
comparison between common pellet textures and pellet breakage behaviour, the textures of intact pellets from the EBF were determined. Pellet pieces in the size range 3.3-6.0 $\mathrm{mm}$ taken out with the shaft probes were characterized for comparison to the textures of pellet pieces after CS-tests.

\subsection{Pellet Strength}

CS-test of pellets taken out with the shaft probes in the EBF was carried out in the PMP. The PMP is a semi-automatic compression strength testing device built by LKAB to enable accurate and repeatable compression strength measurements with possibilities for advanced data analysis. ${ }^{6}$ Twenty pellets can be loaded on a sample tray and crushed one at a time. The piston moves at a rate of $15 \mathrm{~mm} / \mathrm{min}$. For crushing of pellets taken out in the shaft of the EBF, a measuring range $0-100 \mathrm{daN}$ was used. The pressure data is collected by a high-speed data logger and stored in a database. The breakage point of the pellet is determined as the maximum load after which the pressure falls by at least $10 \%$. A high-speed camera can be connected to the PMP instrument for registration of the breakage. ${ }^{7)}$ In the present study of CS of pellets from the EBF shaft, up to 5 pellets from each sub-sample were tested.

The tumbling strength of pellets taken out with the upper shaft probe was tested in an I-drum with a diameter of $130 \mathrm{~mm}$ and a length of $700 \mathrm{~mm}$. Three hundred grams of pellets $>6.0 \mathrm{~mm}$ were rotated 600 times at $20 \mathrm{rpm}$. After tumbling, the sample was sieved for $>6.3 \mathrm{~mm}$ and $<0.5$ $\mathrm{mm}$ and the pellet strength was presented as the percentage of these fractions. Investigations of the tumbling strength of pellets taken out with the lower shaft probe are generally not performed, since pellets gain strength when they are metallized.

\subsection{Light Optical Microscopy}

Light optical microscopy (LOM) was used to characterize pellet textures. For pellets, the largest cross section was characterized. A pellet generally showed different textures at different radial positions and was classified into zones as, for example, periphery, reaction front, intermediate area and core. The extensions of the different pellet zones were not considered in the texture characterizations. In the descriptions of pellet textures, primary particles refer to the texture of iron oxide particles in what is believed to be original untreated particles. A well-sintered texture is a dense texture with extensive contact areas between previous original particles, for which outlines can be visible. Earlier characterization of olivine pellets taken out after quenching and by shaft probes in the EBF showed that the time for cooling can affect the iron oxide and $\mathrm{Fe}_{\text {met }}$ textures. ${ }^{8)}$ In the present investigation, similar types of textures were observed independent of cooling conditions. Occurrence and extension of magnesium ferrite, which is formed during pelletizing, have not been considered in the present characterization. For pellet pieces taken out by the shaft probes and pellet pieces generated in the CS tests, surfaces of fracture were characterized by LOM.

\section{Results}

\subsection{General Pellet Textures}

Pellets taken out at the pelletizing plant contained $\mathrm{Fe}_{2} \mathrm{O}_{3}$ and only in rare cases $\mathrm{Fe}_{3} \mathrm{O}_{4}$ was observed in the pellet core. Figure 2 shows typical textures in the pellet periphery. Primary particles were evident, either appearing slightly sintered and surrounded by smaller particles or in a slightly sintered matrix. Traces of $\mathrm{Fe}_{3} \mathrm{O}_{4}$ were found in large primary particles.

Generally, there was a distinct front between the periphery and the core of the pellet. In some cases, an intermediate area with a combination of the peripheral and core textures was observed. Well-sintered textures with outlines of primary particles, as can be seen in Fig. 3, were most common in the pellet cores. As in the periphery, traces of $\mathrm{Fe}_{3} \mathrm{O}_{4}$ could be found in large primary particles. However, in rare cases a slightly sintered core of $\mathrm{Fe}_{3} \mathrm{O}_{4}$ with traces of $\mathrm{Fe}_{2} \mathrm{O}_{3}$ was identified. Separate primary particles were clearly visible, as observed in Fig. 4. The intermediate area observed between a slightly sintered pellet's core texture and a pellet periphery with visible primary particles exhibited a sintered texture with signs of original particles.
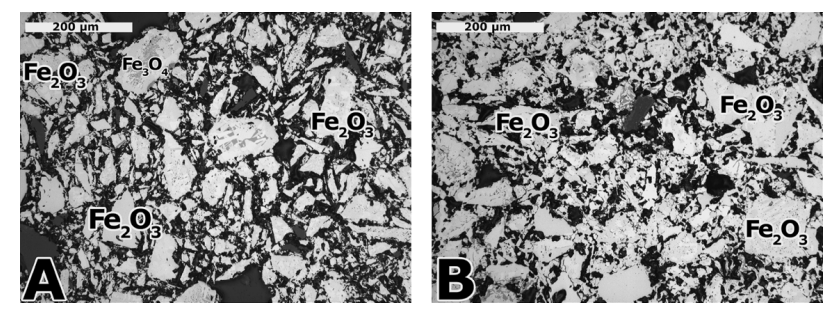

Fig. 2. Typical peripheral textures of pellets taken out at the LKAB pelletizing plant at Malmberget. Slightly sintered primary particles surrounded by smaller particles (A) and a slightly sintered matrix (B). $\mathrm{Fe}_{2} \mathrm{O}_{3}$ with traces of $\mathrm{Fe}_{3} \mathrm{O}_{4}$ in some larger primary particles.
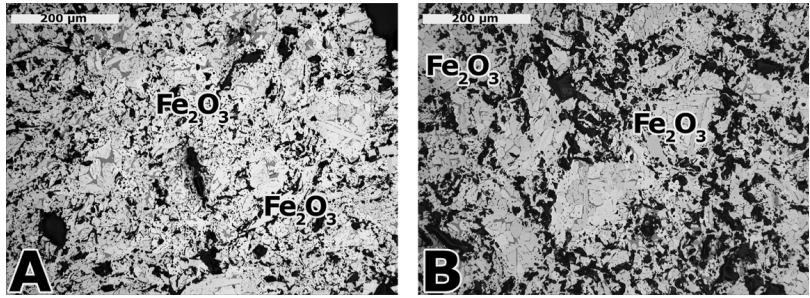

Fig. 3. Typical core textures dominated by $\mathrm{Fe}_{2} \mathrm{O}_{3}$ of pellets taken out at the LKAB pelletizing plant at Malmberget. Pellet core with a dense and well-sintered texture (A), well-sintered with visible outlines of primary particles (B)
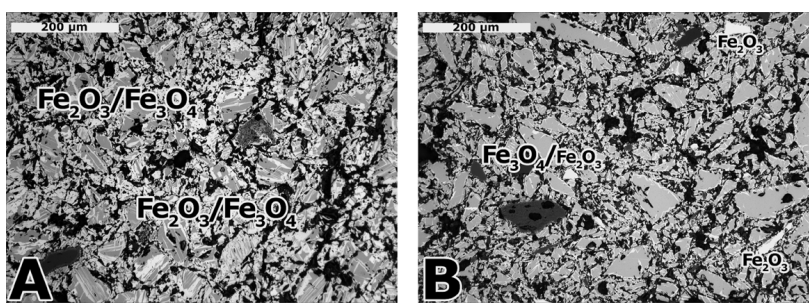

Fig. 4. Rare core textures of pellets taken out at the LKAB pelletizing plant at Malmberget. Slightly sintered primary particles of $\mathrm{Fe}_{3} \mathrm{O}_{4}$ (darker) and $\mathrm{Fe}_{2} \mathrm{O}_{3}$ (lighter). Pores= black. 
At the beginning of reduction in the EBF, $\mathrm{Fe}_{3} \mathrm{O}_{4}$ and wustite formed in the periphery, which was clearly visible in basket sample pellets recovered above the position of the upper shaft probe. Signs of the original peripheral texture were still visible, as can be seen in Fig. 5.

The reduction front was clear, with a mixture of $\mathrm{Fe}_{3} \mathrm{O}_{4}$ and $\mathrm{Fe}_{2} \mathrm{O}_{3}$. Reduction to $\mathrm{Fe}_{3} \mathrm{O}_{4}$ proceeded partly topochemically for each particle or as single areas in a sintered $\mathrm{Fe}_{2} \mathrm{O}_{3}$ texture. In a single pellet, both types of common reduction

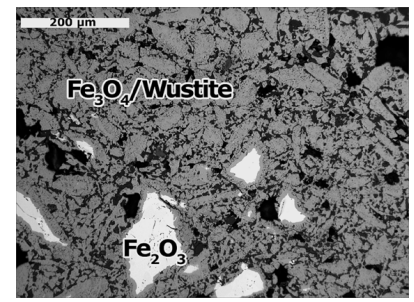

Fig. 5. Typical peripheral texture at commencement of pellet reduction in the EBF. $\mathrm{Fe}_{3} \mathrm{O}_{4}$ /wustite (darker) and $\mathrm{Fe}_{2} \mathrm{O}_{3}$ (lighter). Pores $=$ black.

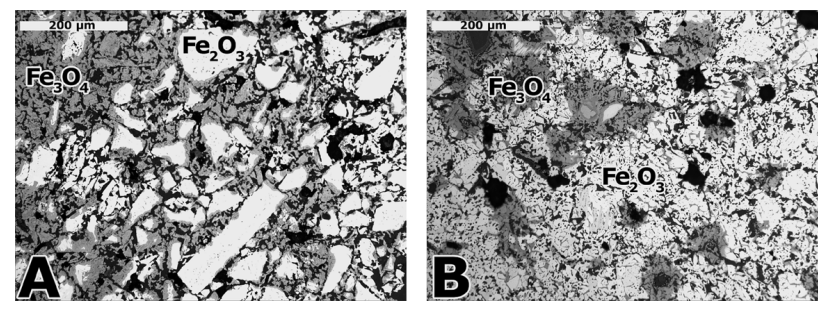

Fig. 6. Typical textures of pellet reduction fronts during reduction from $\mathrm{Fe}_{2} \mathrm{O}_{3}$ till $\mathrm{Fe}_{3} \mathrm{O}_{4}$. Topochemical for each particle (A) and as single areas in well-sintered $\mathrm{Fe}_{2} \mathrm{O}_{3}$ (B). $\mathrm{Fe}_{3} \mathrm{O}_{4}$ (darker) and $\mathrm{Fe}_{2} \mathrm{O}_{3}$ (lighter). Pores =black .
Periphery
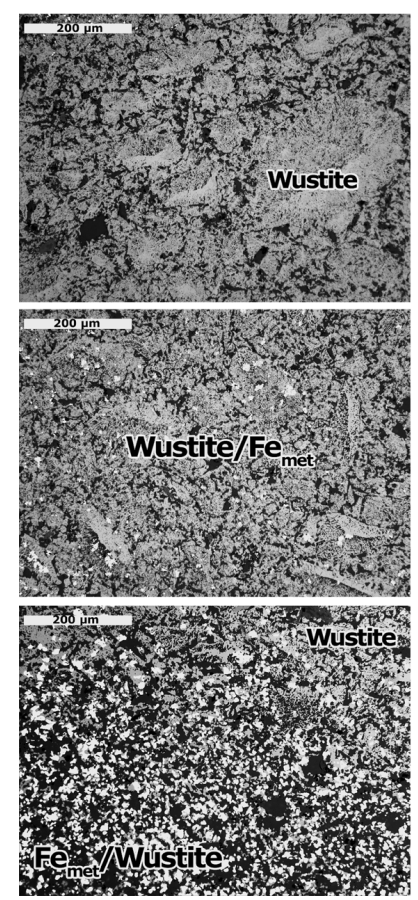

Core
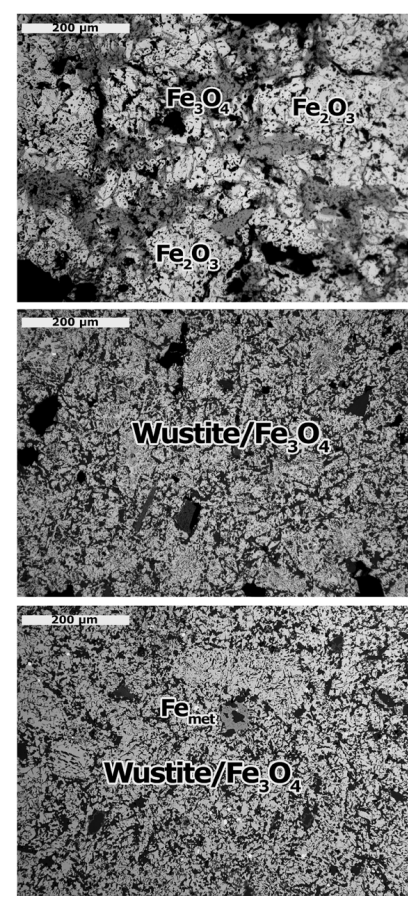

Fig. 7. Typical textures of pellet peripheries (left) cores (right) taken out at the level of the upper shaft probe. $\mathrm{Fe}_{2} \mathrm{O}_{3}=$ light grey, wustite $/ \mathrm{Fe}_{3} \mathrm{O}_{4}=$ grey, $\mathrm{Fe}_{\text {met }}=$ white (lightest) and pores $=$ black. textures could be encountered. Figure 6 shows typical textures of reduction of $\mathrm{Fe}_{2} \mathrm{O}_{3}$. In the pellet core, the original texture was still intact.

At the position of the upper shaft probe, textures containing from $\mathrm{Fe}_{2} \mathrm{O}_{3}$ to $\mathrm{Fe}_{\text {met }}$ were observed, as can be seen in Fig. 7. As wustite $/ \mathrm{Fe}_{3} \mathrm{O}_{4}$ with outlines of primary particles made up the pellet surface and periphery, reduction of $\mathrm{Fe}_{2} \mathrm{O}_{3}$ to $\mathrm{Fe}_{3} \mathrm{O}_{4}$ was observed in the cores. Entire pellets dominated by wustite were observed. In the peripheries, $\mathrm{Fe}_{\text {met }}$ was clearly visible, while only a few small $\mathrm{Fe}_{\text {met }}$ areas were observed in the pellet cores with fuzzy outlines of primary particles. Generally, outlines of primary particles vanished as reduction proceeded. In pellets where reduction had proceeded further, a porous wustite and $\mathrm{Fe}_{\text {met }}$ texture was identified in the pellet periphery. When an intermediate zone was observed between the periphery and core, porous wustite with outlines of primary particles and areas of $\mathrm{Fe}_{\text {met }}$ was most common. In the cores, compact and porous wustite $/ \mathrm{Fe}_{3} \mathrm{O}_{4}$ dominated the texture.

In the shaft below the position of the upper probe, various textures of iron oxides and $\mathrm{Fe}_{\text {met }}$ were observed in bas-
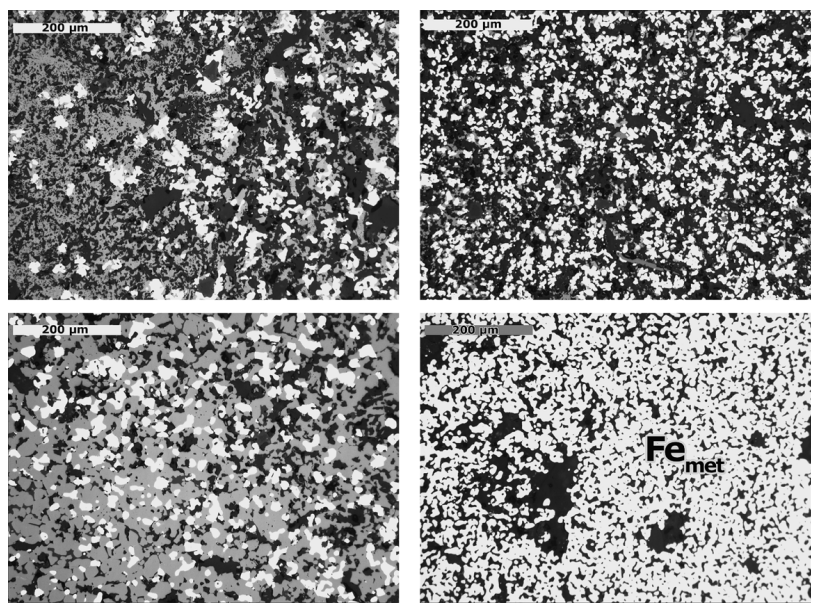

Fig. 8. Common peripheral textures in pellets recovered between the positions of the shaft probes during excavation of the EBF. Wustite $=$ grey, $\mathrm{Fe}_{\text {met }}=$ white (lightest) and pores $=$ black.
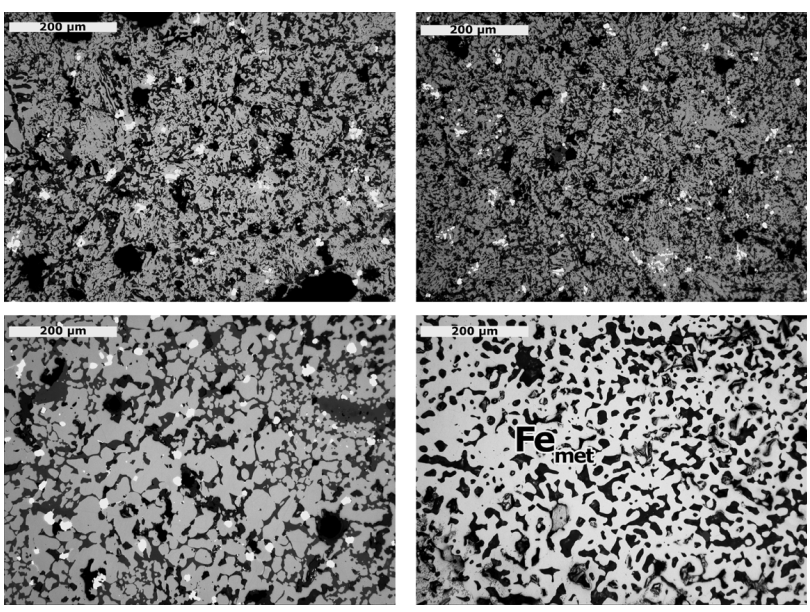

Fig. 9. Common core textures in pellets recovered between the positions of the shaft probes during excavation of the $\mathrm{EBF}$. Wustite $=$ grey, $\mathrm{Fe}_{\mathrm{met}}=$ white (lightest) and pores $=$ black. 
ket samples. Pellet peripheries showed textures with wustite and few areas of $\mathrm{Fe}_{\text {met }}$ as well as fully metallized textures, as can be seen in Fig. 8. Wustite appeared both porous and compact. Isolated $\mathrm{Fe}_{\text {met }}$ areas were compact in a porous matrix. Large variations in pellet textures were observed between individual pellets. In rare cases, slightly sintered primary particles of $\mathrm{Fe}_{3} \mathrm{O}_{4}$ were observed in the pellet core, which then showed similar texture to what was occasionally observed in pellets from the pelletizing plant, see Fig. 4B. In the pellet cores, see Fig. 9, porous or dense wustite with or without areas of $\mathrm{Fe}_{\text {met }}$ were most common. However, rounded wustite appeared with spots of $\mathrm{Fe}_{\text {met }}$. Occasionally, the pellet core was fully metallized.

In pellets taken out with the lower shaft probe, large variations in pellet textures were observed as in the shaft between the probe positions. Pellets showed the same typical texture types as at higher positions in the shaft. Below the position of the lower shaft probe, pellets were made up of $\mathrm{Fe}_{\text {met }}$-textures together with more or less wustite. Pellet cores showed rounded wustite or $\mathrm{Fe}_{\text {met }}$.

\subsection{Shaft Probe Pellet Properties}

\subsubsection{LOM Characterization of Textures}

\subsubsection{Upper Shaft Probe}

Figure 10 shows examples of pellets taken out with the upper shaft probe at estimated centre, i.e. sub-sample 1 of totally 4 , and intermediate, i.e. sub-sample 3 of totally 4 , positions. General texture trends coincided for both sampling occasions. $\mathrm{Fe}_{3} \mathrm{O}_{4}$ and wustite were found in the peripheries of pellets taken out at an estimated centre position. Particles were more or less sintered in the surrounding iron oxides. Separate small areas of $\mathrm{Fe}_{\text {met }}$ were occasionally observed in the pellet peripheries. Reduction from $\mathrm{Fe}_{2} \mathrm{O}_{3}$ to $\mathrm{Fe}_{3} \mathrm{O}_{4}$ advanced in the well-sintered core. Occasionally, $\mathrm{Fe}_{3} \mathrm{O}_{4}$ and wustite were observed in the pellet core, which was surrounded by wustite in the periphery. At estimated intermediate furnace position, pellets had reached a higher degree of reduction. In pellets where wustite and areas of $\mathrm{Fe}_{\text {met }}$ dominated the peripheries, the cores were made up of $\mathrm{Fe}_{3} \mathrm{O}_{4}$ and wustite. Sporadically, small $\mathrm{Fe}_{\text {met }}$ areas could be identified in the cores. Outlines of primary particles were observed in the cores, vanishing towards the pellet surface as the areas of $\mathrm{Fe}_{\text {met }}$ increased. Pellet peripheries of wustite surrounded a core of $\mathrm{Fe}_{3} \mathrm{O}_{4}$ and wustite. However, $\mathrm{Fe}_{2} \mathrm{O}_{3}$ was occasionally still present in the cores and, in rare cases, slightly sintered original particles of $\mathrm{Fe}_{3} \mathrm{O}_{4}$ dominated the texture.

In the shaft probe material sampled in the upper part of the shaft, the 3.3-6.0 mm fraction made up about 1.5-2.0\% regardless of estimated centre or intermediate sampling position. The samples contained pieces of pellets, coke and slag formers. Figure 11 shows textures of pellet pieces in the $3.3-6.0 \mathrm{~mm}$ fraction taken out with the upper shaft probe.

At estimated centre position in the EBF, pellet pieces mainly consisted of $\mathrm{Fe}_{3} \mathrm{O}_{4}$ and wustite. Primary particles were visible and only to some extent slightly sintered and connected to the surroundings, which showed that the material was derived from the pellet peripheries. Occasionally,

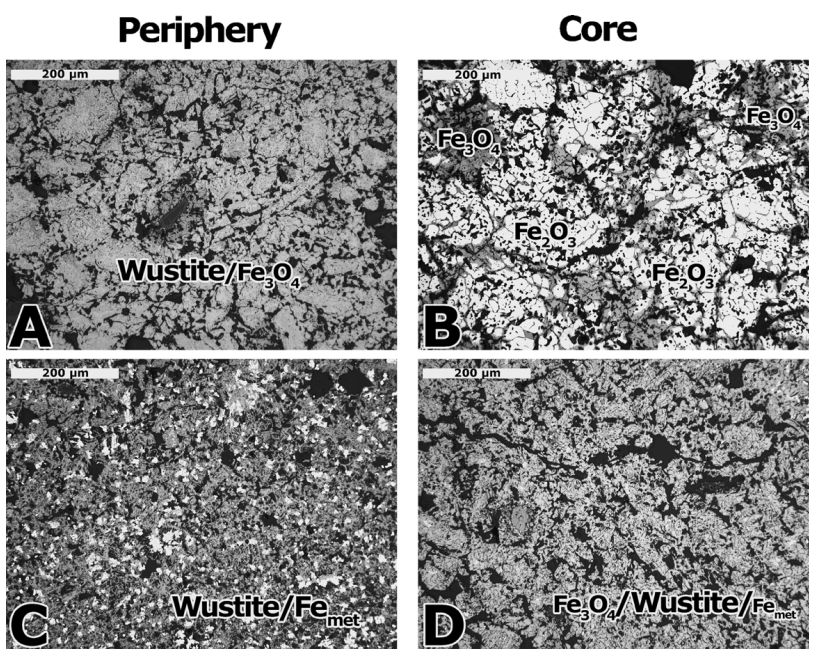

Fig. 10. Textures of pellets taken out at estimated centre $(A, B)$ and intermediate positions (C,D) with the upper shaft probe in the EBF. $\mathrm{Fe}_{2} \mathrm{O}_{3}=$ light grey, wustite $/ \mathrm{Fe}_{3} \mathrm{O}_{4}=$ grey, $\mathrm{Fe}_{\text {met }}=$ white (lightest) and pores $=$ black.
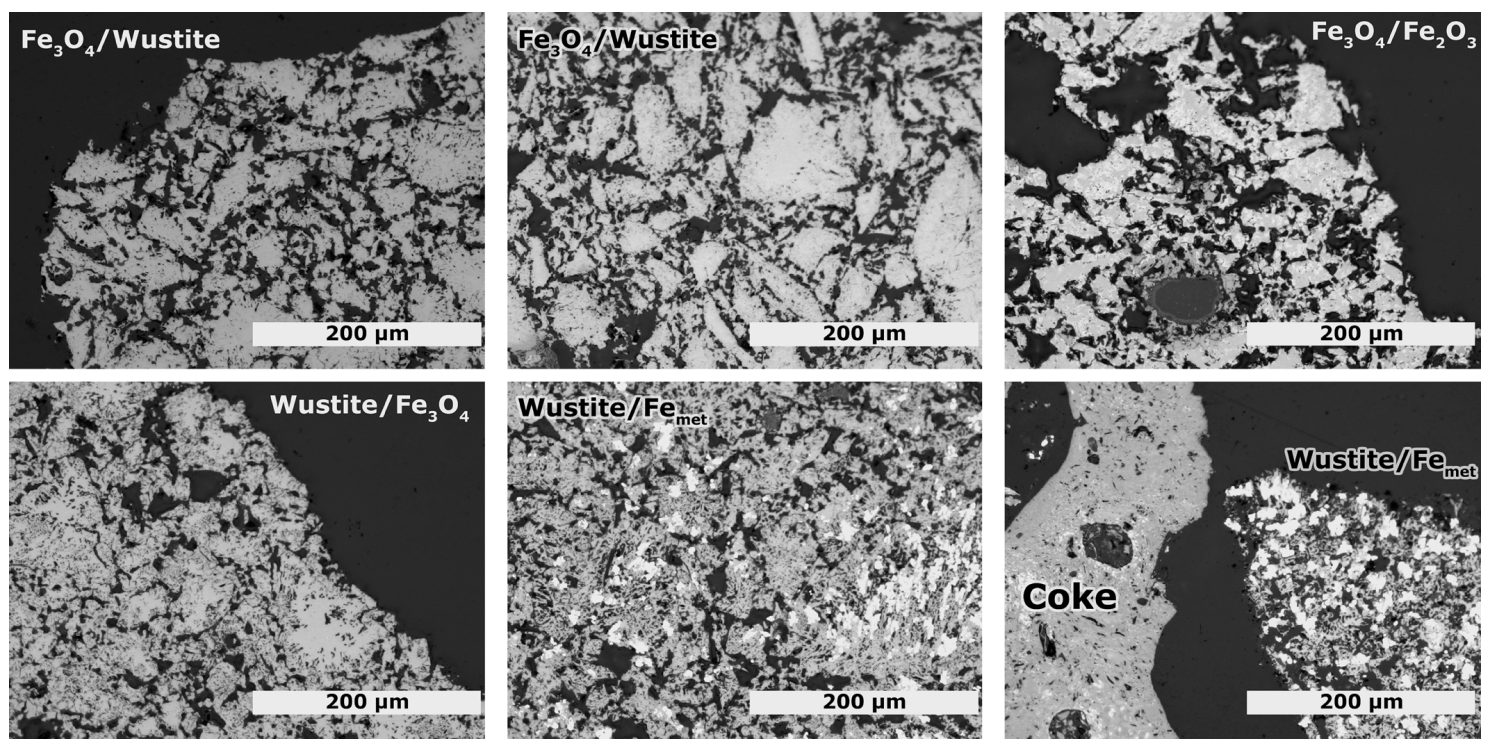

Fig. 11. Typical textures of pieces of pellet in the 3.3-6.0 mm fraction taken out with the upper shaft probe at estimated centre (upper) and intermediate positions (lower). 
$\mathrm{Fe}_{2} \mathrm{O}_{3}$ appeared together with $\mathrm{Fe}_{3} \mathrm{O}_{4}$ in textures which were only slightly sintered and showed primary particles. The texture was recognized from peripheries of pellets recovered in the upper part of the shaft.

In pellet pieces taken out at estimated intermediate position at the level of the upper shaft probe reduction had proceeded further than in the estimated centre part of the furnace. Pieces predominantly made up of wustite were sintered with porosity in the particles as well as around them, although outlines of primary particles were rare. Possible $\mathrm{Fe}_{3} \mathrm{O}_{4}$ remained in compact areas. As well, similar textures were recognized in pellet cores as peripheries, although the occurrence in peripheries was more common, which impeded the determination of the origin of pellet pieces. Identification of $\mathrm{Fe}_{\text {met }}$ in $3.3-6.0 \mathrm{~mm}$ pieces showed generation from the pellet peripheries.

\subsubsection{Lower Shaft Probe}

Figure 12 shows textures of pellets taken out with the lower shaft probe. No systematic texture differences were

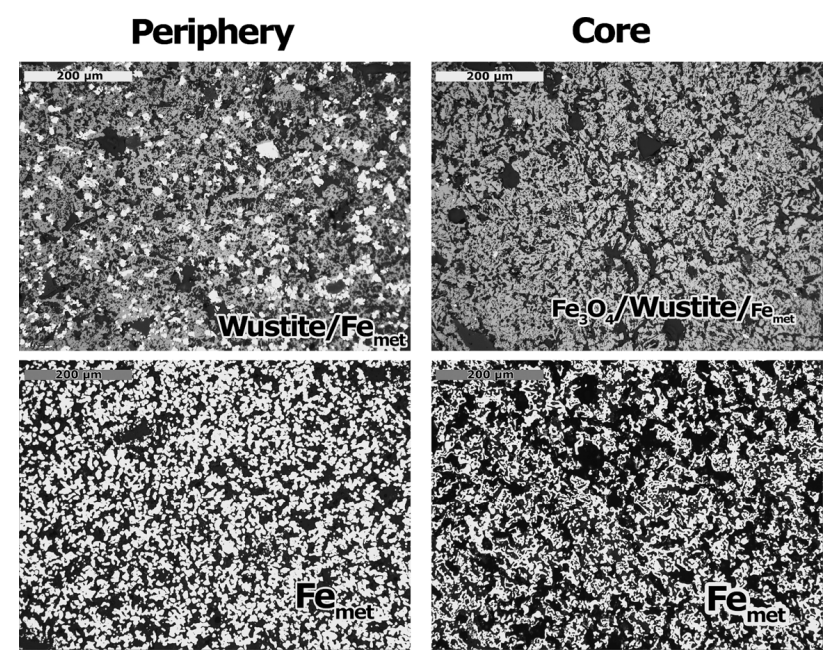

Fig. 12. Textures in pellets taken out with the lower shaft probe. Wustite $/ \mathrm{Fe}_{3} \mathrm{O}_{4}=$ grey, $\mathrm{Fe}_{\text {met }}=$ white (lightest) and pores $=$ black.
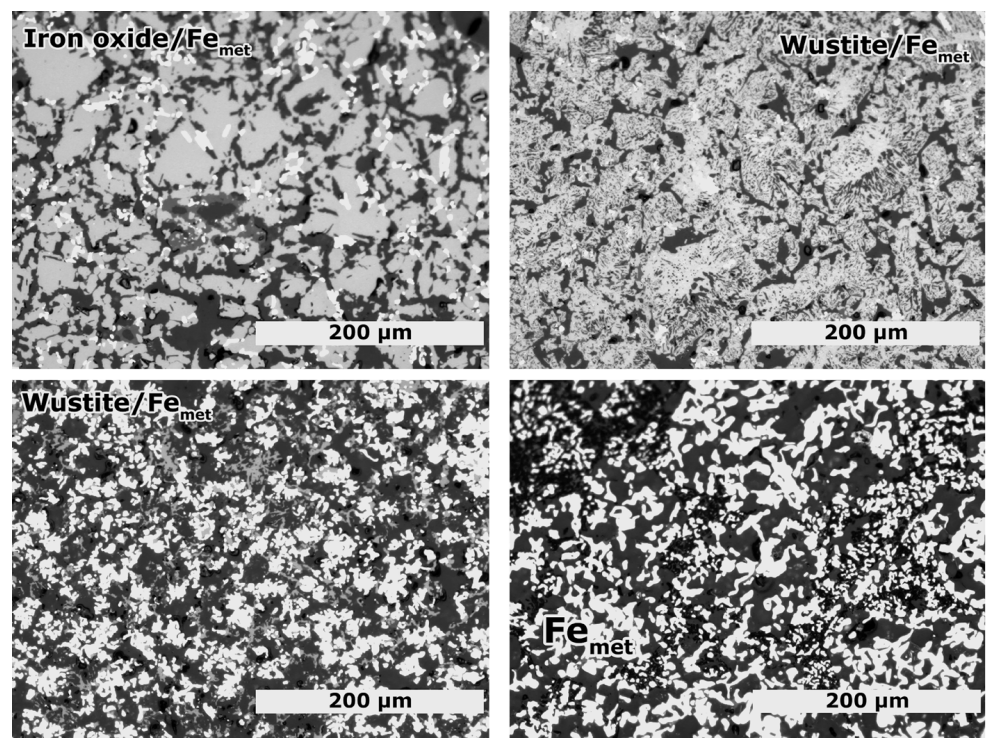

observed between pellets from different radial sampling positions but the texture variations between pellets were extensive. Pellet peripheries usually contained wustite along with more or less $\mathrm{Fe}_{\text {met }}$. The texture was sintered with increasing pore size as the $\mathrm{Fe}_{\text {met }}$ content increased towards the pellet surface. Pellet cores were made up of compact and porous areas of $\mathrm{Fe}_{3} \mathrm{O}_{4}$ and wustite with distributed small areas of $\mathrm{Fe}_{\text {met }}$. Outlines of primary and slightly sintered particles originating from the texture types presented in Fig. 4 could be identified in pellet cores. An intermediate area with a porous texture showing outlines of primary particles occurred when considerable texture differences were observed in the periphery compared to the core. Wustite constituted the major part of the intermediate area in coexistence with $\mathrm{Fe}_{\text {met }}$. Fully metallized pellets occurred.

At the lower shaft probe position, the $3.3-6.0 \mathrm{~mm}$ fraction made up less than $6 \%$ of the total sample regardless of estimated centre or intermediate sampling position. The sample contained material of pellets, coke and slag formers. Figure 13 shows textures of pellet pieces in the $3.3-6.0 \mathrm{~mm}$ fraction. As for pellets, the texture variations were extensive and irrespective of radial sampling position. Wustite and $\mathrm{Fe}_{\text {met }}$ were most common, although some pieces with texture of primary and slightly sintered particles most likely made up of $\mathrm{Fe}_{3} \mathrm{O}_{4}$ were identified. Wustite was porous in the surrounding matrix as well as in the individual grains. $\mathrm{Fe}_{\text {met }}$ and $\mathrm{Fe}_{3} \mathrm{O}_{4}$ were compact with larger pores in the surrounding matrix in comparison to the wustite textures.

\subsubsection{Pellet Strength}

Compression strength of pellets taken out with the upper shaft probe was generally lower or in the same magnitude as for pellets taken out by the lower shaft probe, as seen in Fig. 14. Pellets from estimated intermediate position in the EBF showed higher strength compared to estimated centre samples. Pellets from test period 1 showed higher strength compared to test period 2. A pellet that did not break at the maximum load of the equipment, $100 \mathrm{daN}$, was assigned this value in the calculations of the average strength. Figure 14 also shows the $>6.3 \mathrm{~mm}$ and $<0.5 \mathrm{~mm}$ fractions after I-

Fig. 13. Typical textures of pieces of pellet in the 3.3-6.0 $\mathrm{mm}$ fraction taken out with the lower shaft probe. 
tumbling of pellets taken out with the upper shaft probe. The pellet strength, determined as the percentage $>6.3 \mathrm{~mm}$, was higher for pellets from the estimated intermediate position compared to estimated centre sampling. Simultaneously, the share of fines $<0.5 \mathrm{~mm}$ was lower.

\subsubsection{CS of Upper Shaft Probe Pellets}

A pellet texture with sintered periphery of $\mathrm{Fe}_{3} \mathrm{O}_{4}$-wustite was most common in samples taken out at centre positions with the upper shaft probe but also occurred at intermediate positions. The reaction zone with $\mathrm{Fe}_{3} \mathrm{O}_{4}$ and $\mathrm{Fe}_{2} \mathrm{O}_{3}$, which sometimes extended through the well-sintered core, or wellsintered $\mathrm{Fe}_{2} \mathrm{O}_{3}$ in the core, made up the remaining part of the pellet. Generally, breakage of pellets with this texture classification occurred in two distinct ways. In the most

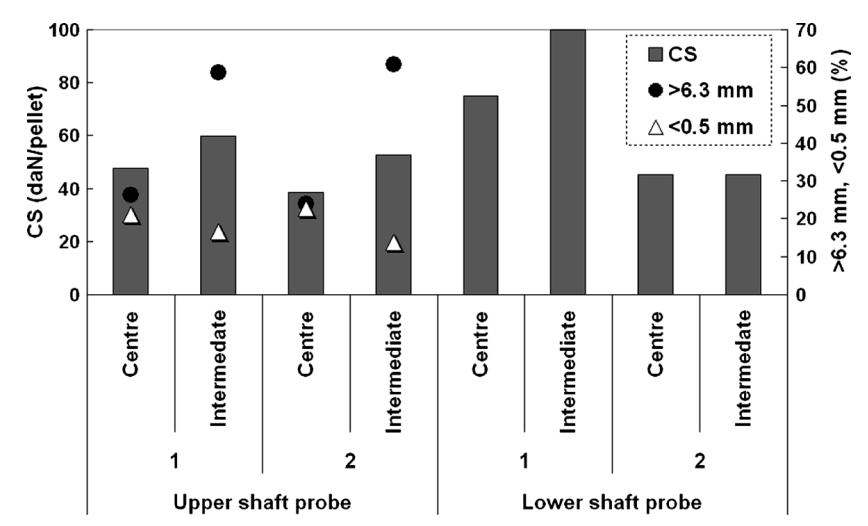

Fig. 14. Average CS results of pellets taken out at estimated centre, i.e. sub-sample 1(4), and intermediate, i.e. sub-sample 3(4), positions at the upper and lower shaft probe positions at two sampling occasions. Pellet strength determined after I-drum tests of pellets taken out with the upper shaft probe. common case, outer layers came off followed by disintegration into pieces of the inner part of the pellet. Alternatively, the pellet disintegrated to pieces right away. The CS of a pellet with the considered texture classification generally exceeded the average value. Pellet breakage, including formation of outer layer pieces, at different stages is show in Fig. 15 as high-speed camera images.

Figure 16 shows LOM images of outer layer and pellet pieces after breakage of the pellet in Fig. 15. The inner surface of the outer layer showed sintered texture with visible outlines of primary particles. In pellets taken out with the upper shaft probe, this texture was identified in the pellet peripheries. After breakage, other pellet pieces contained a sintered texture with areas of $\mathrm{Fe}_{2} \mathrm{O}_{3}$, sometimes together with $\mathrm{Fe}_{3} \mathrm{O}_{4}$, corresponding to the texture in the reaction front or the core of an intact pellet. Pellets that disintegrated immediately to pieces showed areas originating from the pellet periphery as well as the pellet core in one piece. Separate pieces with peripheral, reaction front and core textures were also identified.

Pellets with visible cracks on the surface prior to compression showed CS values below average, as expected. Initial breakage took place at the location of the original cracks. The less sintered textures hampered the CS regardless of location in the pellet.

In pellets taken out at estimated intermediate position with the upper shaft probe, areas of $\mathrm{Fe}_{\text {met }}$ were common in the peripheral texture. LOM characterization of pellet pieces after CS showed that only a few pellets contained the typical texture. However, areas of $\mathrm{Fe}_{\text {met }}$ increased the CS regardless of the additional pellet texture.

\subsubsection{CS of Lower Shaft Probe Pellets}

A texture dominated by wustite, sometimes with areas of
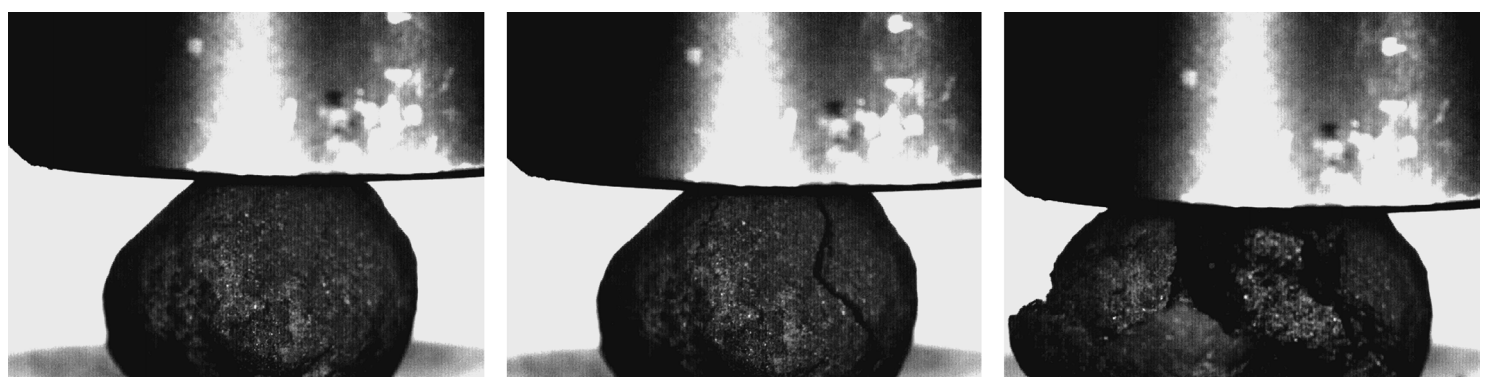

Fig. 15. High-speed camera images of pellet breakage including formation of outer layers of pellet taken out with the upper shaft probe. Intact pellet, primary crack formation and detachment of outer layers.
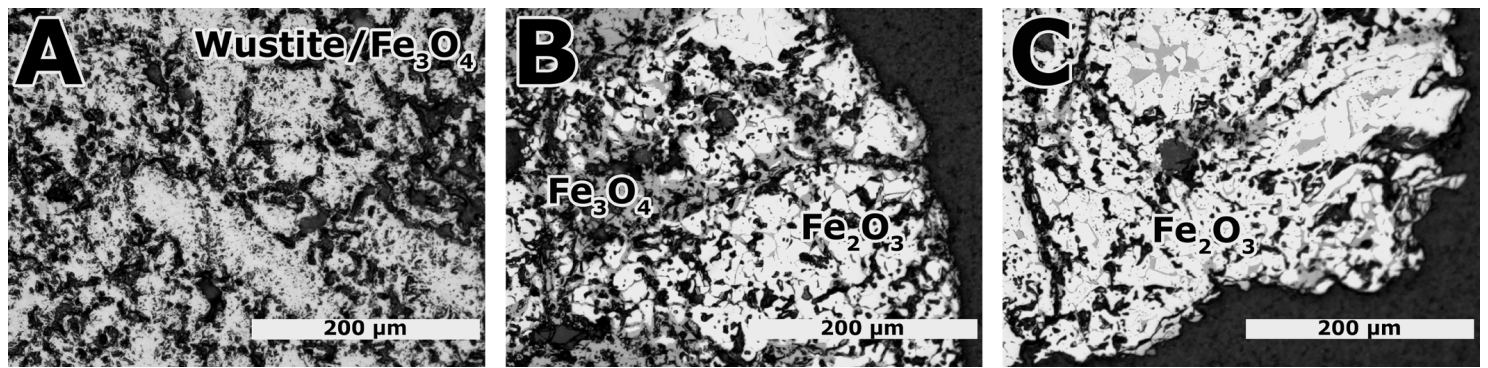

Fig. 16. LOM images of pellet fragments after breakage, as seen in Fig. 15, of pellet taken out with the upper shaft probe. Inner surface of outer layer (A) with wustite- $-\mathrm{Fe}_{3} \mathrm{O}_{4}$, pellet piece from the reaction front between $\mathrm{Fe}_{2} \mathrm{O}_{3}$ and $\mathrm{Fe}_{3} \mathrm{O}_{4}(\mathrm{~B})$ and piece from well-sintered pellet core mainly made up of $\mathrm{Fe}_{2} \mathrm{O}_{3}(\mathrm{C})$. 

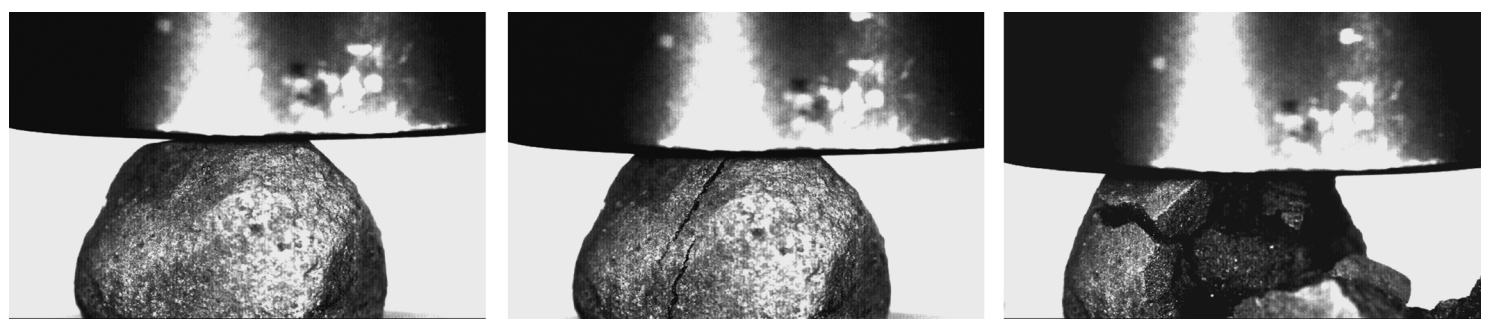

Fig. 17. High-speed camera images of breakage of a pellet taken out with the lower shaft probe. Intact pellet, crack formation and detachment of thick outer layers and appearance of the pellet core.

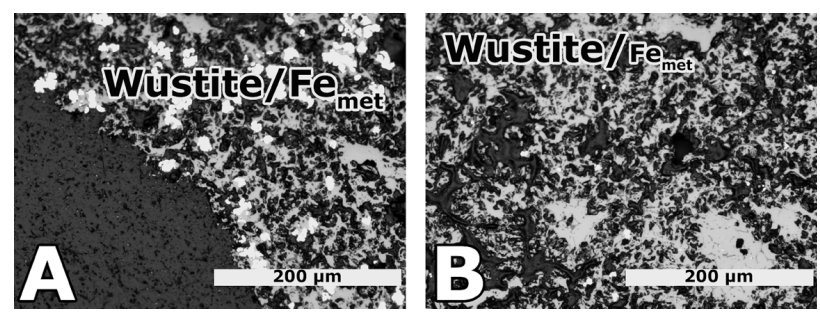

Fig. 18. LOM images of pellet fragments after breakage, as seen in Fig. 17, of pellet taken out with the lower shaft probe. Pieces detached from the pellet periphery with wustite and $\mathrm{Fe}_{\text {met }}(\mathrm{A})$ and pellet core with wustite and minor small areas of $\mathrm{Fe}_{\text {met }}$ (B). Wustite $=$ grey, $\mathrm{Fe}_{\text {met }}=$ white (lightest) and pores $=$ black

$\mathrm{Fe}_{\text {met }}$ mostly located at the periphery, was most common in pellets taken out with the lower shaft probe. Breakage with detachment of outer layers was most common for the porous wustite texture regardless of the presence of $\mathrm{Fe}_{\text {met }}$ areas. After breakage, the pellet core could be identified by the high-speed camera images. Fig. 17 shows breakage pattern including detachment of thick outer layers and appearance of the pellet core.

Figure 18 shows LOM images of pellet pieces after breakage of the pellet shown in Fig. 17. Texture that was similar to one observed in pellet periphery contained wustite and areas of $\mathrm{Fe}_{\text {met }}$. The porosity of wustite varied, while $\mathrm{Fe}_{\text {met }}$ areas were compact in the porous surrounding texture. In the pellet core, outlines of original particles were to some extent visible as compact areas of wustite. The adjacent wustite texture was porous with occasional small $\mathrm{Fe}_{\text {met }}$ areas. Only minor texture differences, with the exception of the $\mathrm{Fe}_{\text {met }}$ content, were detected when comparing peripheral and core pieces.

Visible pellet surface cracks prior to compression resulted in lower CS compared to the average value. Cracks in pellet pieces after CS was observed after some of the tests with lower shaft probe pellets. $\mathrm{Fe}_{\text {met }}$ increased the strength of pellets. A pellet texture with wustite and $\mathrm{Fe}_{\text {met }}$ in the periphery broke at a load of about 50-90 daN. Fully metallized pellets did not break at a load of 100 daN. Less sintered pellet textures showed lower CS values than average.

\section{Discussion}

\subsection{Preservation of Original Pellet Textures through Reduction}

In original pellets from the pelletizing plant, outlines of primary particles were clearly visible in more or less sin- tered surroundings in the pellet periphery made up of $\mathrm{Fe}_{2} \mathrm{O}_{3}$. In the beginning of reduction, the particle outlines remained. However, the in-particle porosity increased during reduction, particularly as wustite was formed. $\mathrm{As} \mathrm{Fe}_{\text {met }}$ appeared the pore size between the particles increased and the primary particle outlines were less visible. At the levels of the shaft probes, the primary particle texture was visible in the pellet peripheries in which reduction had proceeded no further than wustite, which was more common in the upper part of the shaft compared to the lower. At extensive amounts of $\mathrm{Fe}_{\text {met }}$ in the periphery and in presence of rounded wustite and $\mathrm{Fe}_{\text {met }}$, the original peripheral texture was no longer preserved. Below the position of the lower shaft probe, preservation of the original peripheral pellet texture did not occur.

The $\mathrm{Fe}_{2} \mathrm{O}_{3}$ pellet cores from the pelletizing plant were in most cases well-sintered with occasionally vague outlines of primary particles. Since the reduction at commencement was topochemical on a pellet level, unaffected pellet core textures could be observed at upper shaft probe level and above. As the reduction front reached the core, the original texture was still preserved, although $\mathrm{Fe}_{2} \mathrm{O}_{3}$ and $\mathrm{Fe}_{3} \mathrm{O}_{4}$ were found side by side. As porous wustite was the main oxide in the cores, the pores were evenly distributed in the texture, indicating formation from an original texture where the wustite layout probably resembled the original texture. In rare cases, slightly sintered primary particles of $\mathrm{Fe}_{2} \mathrm{O}_{3}$ and $\mathrm{Fe}_{3} \mathrm{O}_{4}$, as seen in Fig. 4, were observed in the core of pellets from the pelletizing plant. The texture was preserved at initial reduction and recognized in the shaft. At the lower shaft probe position, compact areas of wustite existed in cores together with small $\mathrm{Fe}_{\text {met }}$ areas. It could not be determined for certain whether the texture type was based on an originally less sintered pellet core of partly unoxidized $\mathrm{Fe}_{3} \mathrm{O}_{4}$ or an effect of reduction conditions such as ascending gas composition and temperature. However, the relatively extensive presence indicated the latter.

Almost every pellet showed, regardless of reduction degree attained, differences in texture between the periphery and the core. Prior to reduction, there was a distinct transition between the pellet zones, which remained until wustite was the dominating oxide. Differences in textures were still present; however, the transition became fuzzy. It was likely that the texture alternation between periphery and core in a fully metallized pellet took place at the same position as it did in the original pellet. Solely the texture of rounded wustite and $\mathrm{Fe}_{\text {met }}$ appeared equal along the entire pellet diameter and completely razed all signs of the original pellet texture.

The present study has shown prevalence of several types 
of iron oxide and $\mathrm{Fe}_{\text {met }}$ textures at different positions in the EBF shaft. The result is in agreement with earlier characterization of pellets excavated in the EBF shaft. ${ }^{9}{ }^{9}$

\subsection{Properties of Pellets Taken Out with the Shaft Probes}

The PMP equipment was shown to be a suitable tool to determine CS of reduced pellets mainly consisting of iron oxides. The CS-values and I-tumbling results showed similar trends for pellets taken out with the upper shaft probe. The use of the high-speed camera added information about the breakage pattern.

In pellets taken out with the upper shaft probe, the radial sampling position proved to be important for the attained textures. Further reduction was identified in pellet textures from an estimated intermediate position compared to the estimated centre position. As the pellets for CS measurements were selected by random, only a few pellets from the estimated intermediate position with typical porous wustite together with areas of $\mathrm{Fe}_{\text {met }}$ were chosen. Therefore, determination of breakage properties due to characteristic pellet textures caused by radial sampling position was obstructed.

Compression of pellets taken out with the upper shaft probe showed that pieces with peripheral textures of $\mathrm{Fe}_{3} \mathrm{O}_{4}-$ wustite with outlines of primary particles in the most common case came off as outer layers. The breakage strengths were above the average value for results from the upper shaft probe pellets. The different zones of the unbroken pellet appeared after breakage in separate pieces, with the exception of the $\mathrm{Fe}_{2} \mathrm{O}_{3}-\mathrm{Fe}_{3} \mathrm{O}_{4}$ reaction front, which indicated that breakage, at least to some extent, took place at the reaction front. As the pellet diameter on average was expected to be $9-12.5 \mathrm{~mm}$, the outer layer, as seen in Fig. 15, was in the size range of several millimeters. The fractional part of pellet pieces in the shaft probes in combination with the above average pellet strength for the derivation of outer layers indicated negligible degradation at the position of the upper shaft probe or above. Breakage of pellets taken out with the lower shaft probe generated detachment of outer layers in the same manner as was observed for pellets from the upper shaft probe position, although the textures in these cases mainly were made up of porous wustite with or without areas of $\mathrm{Fe}_{\text {met }}$. The average breakage pressure for lower shaft probe pellets sampled during test period 1 was higher compared to upper shaft probe pellets, which could be explained by the more frequent occurrence of $\mathrm{Fe}_{\text {met }}$ at the lower shaft probe level. Since fully metallized pellets did not break at a 100 daN pressure, an even higher breakage could have been expected for pellets with $\mathrm{Fe}_{\text {met }}$ presence through the pellet. It was unclear whether the cracks that were observed in pellet pieces had been introduced in the CS-test or during reduction. If the latter were the case, it might have hampered the pellet strength. Earlier studies on mechanisms in oxidation and sintering of magnetite iron ore green pellets have shown different behaviour in the pellet core and shell. ${ }^{10)}$ A duplex pellet structure with a wellsintered core and less sintered shell may be the result. It was likely that the detachment of outer layers took place at the transition between the core and shell in the original pellet.

Presence of visible cracks on pellet surface resulted in a lower CS than average. The extracted pieces exhibited the same textures as for pellets without surface cracks and thus a higher strength. In the present study, it was not established whether the surface cracks were initiated during the pelletizing stage or at reduction in the upper part of the shaft.

Pellets with a less sintered texture and clearly visible outlines of primary particles showed a lower CS value than average. Occurrence of peripheral as well as core textures in a single pellet piece after CS showed a different breakage pattern compared to the detachment of outer layers. In 3.3-6.0 mm shaft material, pellet pieces did not simultaneously contain textures from the periphery and the core. It was likely that pieces in the shaft of peripheral as well as core parts of a pellet were $>6.0 \mathrm{~mm}$ or had further disintegrated.

According to Fang et al., ${ }^{5)}$ a high-temperature strength of over $1000 \mathrm{~N}(100 \mathrm{daN})$ was sufficient to avoid damage in the blast furnace. In the present investigation, all pellets for CS test were strong enough to withstand stresses in the EBF shaft, although the pressure required for CS was less than $100 \mathrm{daN}$. Thus, CS below $100 \mathrm{daN}$ was sufficient to avoid damage in the EBF. In the present tests, influences of high-temperature properties were not considered.

It could not be determined where the major part of degradation of pellets in $3.3-6.0 \mathrm{~mm}$ fraction took place. Degradation at positions higher in the shaft would cause pellet pieces to descend with the burden. The texture variations were extensive in $3.3-6.0 \mathrm{~mm}$ pieces taken out by the lower shaft probe and pieces originating mainly from the pellet peripheries but also from the cores were observed. Some pieces were fully metallized, while others showed clear outlines of primary particles which were only slightly sintered. The fraction of $3.3-6.0 \mathrm{~mm}$ pieces increased from the upper to the lower shaft probe position. However, the residence time for the material at the lower shaft probe position was increased compared to the upper, and pellets had been subjected to an increased load. Pellets were subjected to successive degradation and fines accumulated as the burden descended in the shaft.

\section{Conclusions}

To investigate the possibilities to use the Pellet Multi Press (PMP) equipment for compression strength (CS) measurements of reduced pellets and to gain a deeper understanding of the correlation between pellet texture and strength, an initial study of pellets taken from the LKAB Experimental Blast Furnace (EBF) was conducted. Furthermore, the pellet pieces generated after compression tests were characterized using light optical microscopy. In order to correlate the texture of pellet pieces to the pellet texture prior to breakage, a characterization of the chronological pellet texture development during reduction in the EBF was performed.

The original pellet texture remained in the beginning of reduction and differences receded through the shaft as wustite and $\mathrm{Fe}_{\text {met }}$ was formed. The original texture influenced pellet strength. A well-sintered texture generated the highest strength.

The PMP equipment was well-suited to study the break- 
age of pellets which were not fully metallized. So far, the results from CS-tests indicated that disintegration of pellets takes place at a reaction front, at transition between different texture types of an iron oxide or at the location of a visible surface crack. However, the results were based on few tests and an extensive investigation will be required to further establish the relation between pellet texture and disintegration. Further, the CS results indicated that $\mathrm{Fe}_{\text {met }}$, even as small areas, improved the strength, while a less sintered texture and visible surface cracks had the reverse effect.

\section{Acknowledgements}

The authors are grateful to the Swedish Energy Agency and LKAB for financial support. The members of the Swedish Steel Producers' Association JK21064 project are acknowledged. The authors extend special thanks to LKAB for providing the opportunity to carry out tests in the EBF and for use of the PMP equipment. A contribution from
CAMM.

\section{REFERENCES}

1) LKAB 2007, Products, (2007), 6, 26.

2) A. Brännmark, A. Dahlstedt, C. Stillberg and G. Hyllander: Proc. of the Iron and Steel Technology Conf., Association of Iron \& Steel Technology, Warrendale, PA, (2007), 315.

3) W. K. Lu and G. Chung: Iron Steelmaker, 30 (2003), 47.

4) B. Hässler: Int. J. Min. Process., 1 (1974), 193.

5) J. Fang, C. Li, X. Wang and R. Ren: Steel Res. Int., 79 (2008), 5

6) S. P. E. Forsmo, A. J. Apelqvist, B. M. T. Björkman and P.-O. Samskog: Powder Technol., 169 (2006), 174.

7) S. Forsmo: Doctoral Thesis, Luleå University of Technology, Luleå, (2007).

8) E. Ryösä: Doctoral Thesis, Uppsala University, Uppsala, (2008).

9) G. Tranell, T. Hagelien, L. Kolbeinsen, A. Dahlstedt and M. Hallin: Proc. of the Iron and Steel Societies 59th Ironmaking Conf., Association of Iron \& Steel Society, Warrendale, PA, (2000), 125.

10) S. P. E. Forsmo, S. E. Forsmo, P. O. Samskog and B. M. T. Björkman: Powder Technol., 183 (2008), 247. 